Bol. Acad. peru. leng. 62.2017 (171-187)

\title{
Semejanzas y diferencias entre el Inca Garcilaso de la Vega y Phelipe Guaman Poma de Ayala
}

\section{Similarities and differences between Inca Garcilaso de la Vega and Felipe Guaman Poma de Ayala}

\author{
JAIME LABASTIDA \\ Academia Mexicana de la Lengua
}

Resumen:

En este artículo interesa comprender las mentalidades de los dos escritores peruanos, semejantes y diferentes a la vez. Los une el tema, sin duda, pero esta es quizá la única coincidencia. Sin embargo, los separa un abismo, porque el tratamiento del tema es radicalmente distinto en ambos autores. El Inca Garcilaso es un mestizo étnico y cultural que escribe desde la cultura cristiana de su padre en la que está inmerso. Su escritura y su mentalidad no son otras que las de un hidalgo español del Siglo de Oro. Otra cosa, distinta, hallamos en la obra de Guaman Poma: la visión de un indígena quechua puro, ladino y cristianizado, que se expresa en una lengua española extraña, impregnada de la cultura y el habla quechuas. Guaman Poma es un hombre de la Edad Mítica y vive inmerso en la etapa económica que llamamos del neolítico superior. El Inca Garcilaso de la 
Vega es, en cambio, un hombre de la Edad de Hierro, un renacentista completo.

\section{Abstract:}

In this article we want to understand the minds of these two Peruvian writers, who are similar and different at the same time. The theme, is without a doubt, what connects them, but this is perhaps the only coincidence. However, there is a chasm separating them because their approaches to the theme is radically different in both authors. Inca Garcilaso is an ethnic and cultural mestizo (offspring of Spaniard and Indian) whose writing comes from the Christian culture of his father in which he is surrounded. His writing and his mentality are none other than a Spanish nobleman of the Spanish Golden Age. Another difference is in the work of Guaman Poma we found the vision of a pure, ladino (Spanish-speaking Indian) and Christianized Indian who expresses himself in a strange Spanish language, embedded in the Quechua culture and language. Guaman Poma is a man of the Mythical Age and lives immersed in the economic stage we call Upper Neolithic. On the other hand, Inca Garcilaso de la Vega is a man from the Iron Age, a complete Renaissance man.

Palabras clave: Inca Garcilaso de la Vega, Phelipe Guaman Poma de Ayala, semejanzas y diferencias.

Keywords: Inca Garcilaso de la Vega, Felipe Guaman Poma de Ayala, similarities and differences. 
El interés por las antigüedades americanas, tanto las de Nueva España cuanto las del Perú, declinan a todo lo largo del siglo XVII y solo cobran nuevo impulso en los inicios del siglo XIX gracias a la influencia decisiva que ejerce el magisterio de Alexander von Humboldt a través de su libro Vues de Cordillères et monumens des peuples indigènes de l'Amérique, cuya publicación se hizo en París en 1810. En este libro, Humboldt examina las culturas amerindias con criterio moderno y científico, ya no a la manera que se hizo en el siglo XVI (para combatir la llamada idolatría). Acaso podría tomarse como fecha simbólica de esta declinación la Historia natural y moral de las Indias, libro del jesuita Joseph de Acosta editado en Sevilla en 1590; pero, de igual manera, la publicación de los Comentarios reales, que tratan de los Yncas, reyes que fueron de Perú, por el Inca Garcilaso de la Vega, que se editó en 1609. Menos de veinte años separan la edición de estas dos obras que son, sin embargo, los últimos textos (públicos) de interés por las altas culturas de América. A ellos podría sumarse el manuscrito de Phelipe Guaman Poma de Aiala (o Phelipe Huaman Puma de Ayala), Nueva Corónica i buen gobierno, escrito durante treinta y dos años, de modo lento y trabajoso (fue terminado en 1616, el mismo año de la muerte del Inca Garcilaso, en calidad de informe de la situación reinante en Perú al rey Felipe III), y se conoció solo en 1908, perdido como estaba en la Biblioteca Real de Dinamarca ${ }^{1}$. En esa lista caben los textos de algunos escritores de Nueva España que, como el de Guaman Poma, permanecieron inéditos durante varios siglos.

1 Phelipe Guaman Poma de Ayala. El primer nueva corónica i buen gobierno. 
Aquí y ahora me interesa tratar de comprender las mentalidades de los dos escritores peruanos, semejantes y diferentes a la vez. Los une el tema, sin duda, pero esta es quizá la única coincidencia. Los separa un abismo, no vacilo en decirlo, porque el tratamiento del tema es radicalmente distinto en ambos autores. El Inca Garcilaso es un mestizo étnico y cultural que escribe desde una clara perspectiva: la cultura cristiana de su padre en la que está inmerso por completo. Su escritura y su mentalidad no son otras que las de un hidalgo español del Siglo de Oro. Su visión de la cultura incaica se produce a la distancia: es la de un cristiano renacentista que vive en plena contrarreforma. Lo mismo se halla en el jesuita Joseph de Acosta, en tanto que otra cosa, distinta, hallamos en la obra de Guaman Poma: la visión de un indígena quechua puro, ladino y cristianizado, es cierto, que se expresa en una lengua española extraña, impregnada de la cultura y el habla quechuas. De allí que, como señala con precisión Jorge L. Urioste, el estilo de la escritura de Guaman Poma sea «complejo, difícil», pues parece tener «una gramática propia, muy distinta de la del español de la época». Urioste añade que da la impresión de que Guaman Poma hubiera traducido su texto desde un original quechua, razón por la que su español acusa una extrema influencia de su lengua materna. Desde luego, no es así: no hay ningún texto quechua en el que Guaman Poma pudiera apoyarse. El español del Inca Garcilaso está conforme, en cambio, con la norma culta del Siglo de Oro. En el Inca Garcilaso, la cultura quechua se incrusta en un tronco hispánico; en Guaman Poma la cultura y 
la historia hispana y cristiana se incorporan al tronco amerindio quechua, que impregna toda su concepción del mundo. Garcilaso es un hombre del Renacimiento; Guaman Poma es un hombre de mentalidad mítica.

Para captar de mejor manera la textura del pensamiento del Inca Garcilaso, acaso sea conveniente ponerla en contacto con los textos de otros contemporáneos suyos, pertenecientes a la Nueva España. Hablo de escritores mestizos como él, que delatan propósitos semejantes. Estos escritores son coetáneos del Inca Garcilaso y su objetivo es prácticamente el mismo. Sus textos, de carácter histórico, dan cuenta de un pasado glorioso, perdido: el que posee su rama materna (la inca en un caso, la nahua en otro, y por esto son hoy, en ambas naciones americanas, exaltados en calidad de raíz original). Los escritos novohispanos se producen bajo la forma de lo que entonces recibía el nombre de probanza de méritos (para solicitar mercedes reales). Hijos de algún conquistador hispano, estos mestizos (étnicos y culturales a la vez, como el Inca Garcilaso) descienden de alguna princesa india o alguna señora de la nobleza indígena. Sus nombres delatan sus orígenes: unen al apellido español, del padre, el apellido indígena, de la madre. La situación de Garcilaso es la inversa: se llamó, al ser bautizado, Gómez Suárez de Figueroa, pero adoptó otro nombre al escribir: Inca Garcilaso de la Vega, donde el nombre quechua precede al del padre hispano. Los autores novohispanos se llaman, pues, Fernando de Alva Ixtlilxóchitl o Hernando Alvarado Tezozómoc. Ixtlilxóchitl escribe hacia finales del siglo XV y al dar inicio 
el siglo XVII; Tezozómoc, unos años antes, pero sus obras permanecen inéditas durante siglos ${ }^{2}$.

Recojo un texto de Ixtlilxóchitl, sintomático. Dice: «fue importantísima cosa la ayuda que tuvieron de Tezcoco los españoles», o sea, la ayuda que recibieron de su antepasado, el último tlahtoani o señor de Texcoco, poblado cercano a México-Tenochtitlan (que se llamó como él, Ixtlilxóchitl), «que después de Dios, Ixtlilxuchitl y demás hermanos y deudos suyos, señores y caudillos que ellos eran, se plantó la ley evangélica, y se ganó la ciudad de México, y otras partes y provincias...». Añade:

y me espanta de Cortés, que siendo este príncipe el mayor y más leal amigo que tuvo en esta tierra, que después de Dios con su ayuda y favor se ganó, no diera noticia de él ni de sus hazañas y heroicos hechos, ya que no se le dio ningún premio; sino que antes lo que era suyo y de sus antepasados se le quitó.

Aún más expresiva es la queja de Ixtlilxóchitl en este otro pasaje: «desde que los españoles llegaron a esta Nueva España siempre» los señores de Texcoco «los obedecieron, y siempre fueron y han sido leales vasallos de S. M.». Sin embargo, dice

siendo como somos Señores naturales [...] y haber tenido y poseído mucha cantidad de tierras y pueblos [...] y siendo los mejores indios de la Nueva España, y los que con mejor título éramos Señores de lo que teníamos,

2 Fernando de Alva Ixtlilxóchitl, Obras históricas. En Bernardino de Sahagún. Historia de las cosas de Nueva España, se ofrece, en el tomo IV, en forma de apéndice, la «Relación sobre la venida de los españoles». Ver la obra de Hernando Alvarado Tezozómoc. Crónica mexicana, escrita hacia el año de 1598. 
después de haber venido españoles a esta Nueva España $\mathrm{y}$ habiéndonos tornado cristianos de nuestra propia voluntad, porque tenemos conocido el error en que primero estábamos [... porque] después de habernos puesto bajo el dominio de S. M. [...] se nos han quitado todos los pueblos y tierras y mando que teníamos [...] de lo cual hemos recibido y recibimos notorio agravio, y vivimos muy pobres y necesitados y sin ninguna renta [...] nos han desposeído de lo nuestro, y desheredado, y héchonos tributarios, cuando no lo éramos [...].

La queja de Ixtlilxóchitl concluye: «nosotros, descendientes de la Real Cepa, estamos tasados contra todo el derecho [...]» (Sahagún 1956: XX) ${ }^{3}$.

Se advierte que Fernando de Alva Ixtlilxóchitl se asume como el heredero de los privilegios reales de su antepasado, en tanto que exige títulos de propiedad, de tierras y de pueblos, al más puro estilo jurídico castellano, que de ninguna manera existían entre los amerindios. También se advierte el fatal resultado de esa alianza entre el señor de Texcoco, Ixtlilxóchitl, y Hernán Cortés: sus descendientes, entre otros, el propio Fernando de Alva Ixtlilxóchitl, que ochenta años después redacta su probanza de méritos, recibieron de las autoridades virreinales, como recompensa, el despojo de todas las prebendas de que gozaban antes de la conquista. ¿Es el caso del Inca Garcilaso, en tanto que heredero del linaje de su madre, una coya, es decir, una supuesta princesa? Por parte de padre, el Inca Garcilaso se integró, de manera total, en la cultura y las costumbres españolas: fue soldado hispano, escribió en un español pulido, vivió y

3 Fernando de Alva Ixtlilxóchitl, en Sahagún, op. cit., pp. 205 y 212. La otra cita pertenece al tomo I de sus Obras históricas, pp. 445-446. 
murió en la península ibérica y publicó sus libros lo mismo en España que en Portugal, por ese entonces unido a la Corona española. Empero, como Ixtlilxóchitl, el Inca Garcilaso intentó, de manera inútil, que se le restituyera el patrimonio familiar del que había sido despojado en Perú.

Veamos cómo finaliza el Libro IX de los Comentarios reales, cuyo título es sin duda significativo, «La descendencia que ha quedado de la sangre real de los Incas». Dice Garcilaso que ha recibido carta desde Cuzco con fecha 16 de abril de 1603, en la que varios principales le solicitan interceder ante el rey para que les devuelvan los privilegios perdidos; la letra en que está escrita esa carta es «muy linda», dice el Inca Garcilaso, y «el frasis o lenguaje en que hablan, mucho dello es conforme a su lenguaje y otro mucho a lo castellano, que ya están todos españolados». Añade que no pone la carta en su libro "por no causar lástima con las miserias que cuentan», ya que desean que el rey dé fin a sus sufrimientos y puedan así recuperar las tierras y los pueblos de los que han sido injustamente despojados (Garcilaso de la Vega 1943: 295-297, libro IX, t. II). Se trata, pues, de una petición al rey para que les haga mercedes, apoyada en una probanza de méritos.

Señalo estos puntos de contacto estrecho entre dos historiadores de los dos principales virreinatos americanos, el de Perú y el de Nueva España porque, según entiendo, la semejanza de los propósitos que persiguen y los magros, por no decir nulos resultados políticos y económicos obtenidos, están en orden inverso a la reciedumbre de su prosa y al mérito literario que reconocemos hoy en sus escritos. 
Hecha esta comparación, entro de lleno en otra, de relevancia mayor: la que existe entre las concepciones del Inca Garcilaso y la cosmovisión de Guaman Poma. Desde que se inician los Comentarios reales, se percibe con claridad la mentalidad que prima en el Inca Garcilaso: la de un occidental que hace la descripción física del planeta, de modo sucinto, es cierto, pero apoyado en conceptos que son propios de la geografía de su época: habla del Trópico de Capricornio, de las zonas templadas y las zonas tórridas, de la existencia de antípodas, de que hay un mundo y solo uno (aunque se hable de «Viejo» y «Nuevo» Mundo), del carácter de la lengua quechua, de la ausencia de moneda labrada en el Perú, de la manera como fue descubierta América, del nombre del país, de la religión de los incas (idolátrica, desde luego), de los sacrificios que hacían los antiguos habitantes del Perú, en fin, ¿a qué seguir? Subrayo que la diégesis asumida por el Inca Garcilaso es lineal, a la manera en que se desarrolla el tiempo en la concepción de Occidente y cuanto apunta en su texto denota, diré una obviedad, su concepción occidental del mundo y la cultura.

Otro, muy distinto, es el modo como se despliegan la escritura y la gráfica de la Nueva corónica de Guaman Poma. Cabe centrar la atención en lo que conforma el desarrollo propio del texto de Guaman Poma: cómo nació el mundo. Al parecer, se trata de una mera repetición del relato bíblico que se halla en el Génesis. No es así. Guaman Poma incorpora al proceso genesíaco, descrito en la Biblia, la concepción quechua de la creación del mundo o, dicho de modo mejor, cómo surge la Tierra de las aguas primordiales. El nacimiento se 
produce en cinco etapas sucesivas. De este proceso me he ocupado con algún pormenor en otro texto, leído aquí mismo, en Lima, en 2013, razón por la que ahora me limito a exponer sus rasgos esenciales (Labastida 2014). En la primera edad se hallan Adán y Eva en el mundo: el varón es dibujado con la herramienta amerindia de labranza, la coa; Eva está cubierta con pieles y sostiene en sus brazos a dos niños. Se percibe que, de acuerdo con Guaman Poma, Adán es un labrador a la manera quechua, un campesino de los Andes. Sobre Adán y Eva se hallan el Sol y la Luna, además de dos aves de corral (gallina y gallo). La segunda etapa (o el Segundo Mundo) corresponde al diluvio y en él está Noé. La tercera edad del mundo es la de Abraham. La cuarta se identifica con el rey David y la quinta arranca del nacimiento de Jesucristo al día de hoy (Guaman Poma 1980: 16-ss.). No hay en el relato de Guaman Poma, por lo tanto, un acto único de creación, obra de la palabra divina, ni el mundo es creado en el espacio de seis días, como en el Génesis (donde se mide el tiempo por semanas: las cuatro fases de la Luna, de siete días cada una, a la manera hebrea). En Guaman Poma, por el contrario, el mundo nace en cinco etapas, como en las cosmogonías amerindias, sean quechua, náhuatl o maya. En todas, el centro ceremonial con el que esos pueblos se identifican (Cuzco, México, Chichén) emerge de las aguas primordiales en que estaba sumergido. De paso, diré que el nombre náhuatl para el centro ceremonial con el que el pueblo se identifica y del que cobra su origen, su ombligo, su axis mundi, recibía el nombre de Altepetl, voz formada por dos raíces: atl, agua, y tepetl, cerro: montaña o pirámide que nace del agua. 
Guaman Poma dice que en esa quinta edad, cuando nació Jesucristo, empezó a reinar en la ciudad de Cuzco el primer inca, Manco Capac. Para nuestro asombro, empero, páginas adelante, Guaman Poma retoma el proceso de creación del mundo desde una perspectiva geográfica distinta, la americana; mejor, desde el Cuzco, los incas y el Perú. Hay otra vez una primera edad del mundo, la Primera generación de indios, Vari Vira Cocha; luego, la segunda generación de indios, Vari Runa; después, la tercera generación, Purun Runa, tras de la cual viene la cuarta generación, Auca Runa, y a partir de ella se abre la quinta edad, donde reinan, dice Guaman Poma, los Ingas, legítimos descendientes de Adán y Eva y multiplicos de Noé. También para nuestro asombro, el primer inca es dibujado por Guaman Poma del mismo modo que Adán: con una coa en la mano (Guaman Poma 1980: 40-ss.). Es evidente que Guaman Poma describe una cultura agrícola y sedentaria pero, tanto en Europa como en América, al estilo de los campesinos amerindios.

Podríamos destacar otros rasgos para mostrar la semejanza estructural que existe entre las culturas andina y mesoamericana. Me limito a dos. El ayllu incaico guarda estrecha similitud con el calpulli náhuatl. Ayllu, dice el gran lingüista Ángel Rosenblat, es barrio o linaje. Se advierte en el significado de ayllu, confundidas, dos entidades en apariencia distintas: ayllu, ¿es barrio o linaje? Si es barrio y linaje a un tiempo, quiere decir que estas dos entidades se unen por razones válidas. Se trata, en rigor, de un linaje (en términos antropológicos debiera decirse: un clan) que se asienta en una cierta porción de terreno (en un barrio) del que el clan o el linaje ha cobrado posesión colectiva. 
El calpulli náhuatl posee rasgos semejantes al ayllu, sin duda. Asienta Alonso de Zorita, Oidor de la Segunda Audiencia de la Nueva España, que calpulli significa «barrio de gente conocida o linaje antiguo, que tiene de muy antiguo sus tierras y términos conocidos, que son de aquella cepa, barrio o linaje»; añade: «estas tierras no son en particular de cada uno del barrio, sino en común del calpulli, y el que las posee no las puede enajenar, sino que goce de ellas por su vida, y las puede dejar a sus hijos y herederos» (s. f.: 87) ${ }^{4}$. A su vez, la mit'a incaica es semejante al tequitl nahua: el tributo, en especie o trabajo, que el pueblo otorga a sus señores. En ningún caso se trata de un trabajo voluntario, sino forzado, por el que la etnia dominante exige a los pueblos sometidos un servicio gracias al cual se construían pirámides o se realizaban obras colectivas: sistemas de riego, puentes, caminos...

Abrigo la certeza de que este conjunto de semejanzas entre la cosmovisión de pueblos alejados por miles de kilómetros y que carecían de cualquier contacto entre sí, se deriva de una situación económica que se encuentra en el mismo grado de desarrollo de sus fuerzas productivas. Esto hace que, por lo tanto, posean rasgos comunes: ambas civilizaciones vivían en el seno de la revolución neolítica, es decir, trabajaban la piedra tallada. Los hombres de la Edad Mítica obtuvieron hallazgos técnicos asombrosos, de los que somos herederos todavía hoy. Los hombres de la Edad Mítica, en las riberas del Nilo o el Éufrates, en las del Ganges

4 He reproducido el texto de Zorita como apéndice en Lewis H. Morgan y Adolph Bandelier. México antiguo (2004). 
o del Yang Tsé, en la cuenca lacustre de México o en las alturas de los Andes, domesticaron las plantas y los animales que aún nos acompañan y que no han abandonado nuestras casas. Desde aquellas lejanas fechas, la sociedad humana no ha logrado domesticar ningún otro animal, ninguna otra planta. No elevemos reproche alguno contra el supuesto atraso de aquellas sociedades: caballos, toros, cerdos, llamas, trigo, maíz, papa, arroz, frijol, perros, gallinas, guajolotes, cebada, caña de azúcar son herencia de los pueblos egipcio, chino, hindú, mesopotámico, andino, mesoamericano...

Cierto, aquellos pueblos desconocieron el hierro y la escritura apoyada en el análisis fonético del lenguaje. Pero sabían conservar sus tradiciones y sus leyes por medio de instrumentos de memorización y de oralidad asombrosos. Los nahuas se basaban en códices pintados y en glifos que, según Humboldt, hablaban a la vez a los ojos y a los oídos. Los incas, por su parte, a través de quipus, llevaban las cuentas de los tributos y hacían relatos puntuales de cuanto acontecía en su entorno. Hay más cosas, pues, entre el cielo y la Tierra de las que sueña la filosofía de Horacio...

De una estructura económica semejante se desprende la enorme similitud que tienen las concepciones del mundo de mesoamericanos e incas. Véase, si no, el mapamundi de las Indias, que dibuja Guaman Poma en su Nueva corónica, guarda estrecha relación con la Piedra del Sol de la cultura mexica y, desde luego, con la primera lámina del códice Fejérváry-Mayer, mexica y precortesiano de igual modo. El mapamundi de Guaman Poma muestra una gran isla y en su centro, el Cuzco. El mapamundi se ofrece, como la Piedra del Sol, desde los 
ojos del astro. En la parte superior del mapa no se halla el norte sino el oriente y a la mano izquierda del Sol se ofrece la región austral, mientras que a su derecha está el septentrión. La Piedra del Sol no fue hecha para que la contemplara el pueblo mexica; por el contrario, el Sol, ser vivo, aunque esté labrado en piedra, acecha. Por esa causa, Huitzilopochtli, el Sol, es llamado Colibrí del Sur o Colibrí Zurdo: nace el 21 de diciembre, el solsticio de invierno. Si vemos de frente hacia el oriente cuando sale el Sol, a la izquierda está el norte magnético; pero, si el Sol es un ser vivo que nos ve, a su izquierda está el sur. Por esto, Huitzilopochtli, al nacer, cuando brilla en el cielo del amanecer y en el curso del día, mata a sus hermanos, los Centzonhuiznahuac, los Cuatrocientos o Innumerables del Sur, los astros, y degüella a su hermana, Coyolyauxqui, la Luna. Pero esas muertes son tan solo simbólicas, mejor, míticas: sucede lo inverso por las tardes: los astros matan al Sol, que entra en las fauces de la Tierra.

El Tahuantinsuyo representa las cuatro porciones de la superficie terrestre, más un punto central: el axis mundi, el ombligo, en este caso, el Cuzco (según Ángel Rosenblat, esto significa Cuzco: ombligo). El número cinco es fundamental en todas esas cosmogonías; es el número perfecto: muestra las cuatro partes de la superficie terrestre y el centro, el lugar de privilegio, el sitio sagrado del pueblo, o sea, Cuzco, México, Machu Picchu, Luxor, Chichén, los centros ceremoniales con los que cada pueblo se identifica. Guaman Poma es un hombre de la Edad Mítica y vive inmerso en la etapa económica que llamamos del neolítico superior. El Inca Garcilaso de la Vega es, en cambio, un hombre de la 
Edad de Hierro, un renacentista completo. Ninguno de los dos tuvo ningún texto quechua a partir del cual pudieran traducir al español sus relatos. Ambos se valieron de las tradiciones orales del pueblo incaico. De allí su grandeza, que se acrecienta el día de hoy. 


\section{Bibliografía}

ACOSTA, Joseph de. Historia natural y moral de las Indias. Edición, prólogo y apéndice de Edmundo O'Gorman. México, Fondo de Cultura Económica, 1962.

ALVA IXTLILXÓCHITL, Fernando de. Obras históricas en dos volúmenes (tomo I, Relaciones; tomo II, Historia chichimeca). Edición preparada por Alfredo Chavero. México, Secretaría de Fomento, 1891.

ALVARADO TEZOZÓMOC, Hernando. Crónica mexicana, escrita hacia el año de 1598. Notas de Manuel Orozco y Berra. México, Editorial Leyenda, 1944.

GARCILASO DE LA VEGA, Inca. Comentarios reales de los Incas. 5 volúmenes. Edición al cuidado de Ángel Rosenblat. Buenos Aires, Emecé Editores, 1943.

GUAMAN POMA DE AYALA, Phelipe. El primer nueva corónica i buen gobierno. Edición crítica de John V. Murra y Rolena Adorno. México, Siglo XXI Editores, 1980.

HUMBOLDT, Alexandre de. Vues de Cordillères et monumens des peuples indigènes de l'Amérique. París, Chez E. Schoell, 1810, dos volúmenes in folio. Hay edición española, Alexander von Humboldt, Vistas de las cordilleras y monumentos de los pueblos indígenas de América. Traducción y estudio preliminar de Jaime Labastida. México, Siglo XXI Editores, 1995, dos volúmenes.

LABASTIDA, Jaime. «Lengua y mundo en la obra de Phelipe Guaman Poma de Ayala», en Boletín de la Academia Peruana de la Lengua. Lima, Academia Peruana de la Lengua, 2014, págs. 13-39. 
MORGAN, Lewis H. y Adolph BANDELIER. México antiguo. Edición y prólogo de Jaime Labastida. México, Siglo XXI Editores, 2004.

SAHAGÚN, Bernardino de. Historia general de las cosas de Nueva España. Edición preparada por Ángel María Garibay. México, Editorial Porrúa, 1965, 4 v.

ZORITA, Alonso de. Breve relación de los señores de la Nueva España, en Pomar y Zurita, Varias relaciones antiguas. México, Editorial Salvador Chávez Hayhoe, s. f. 